\title{
An Analysis on Social and Cultural Background of the Resistance for China's Education Reform and Academic Pressure
}

\author{
Wei Li \\ School of Literature and law, Shandong Broadcast and TV University \\ 10 Shungeng Road, Jinan 250014, China \\ Tel: 86-531-8559-7156 E-mail: diandalw@sina.com
}

Yuxin Li

Institute for Employment Research, University of Warwick

Social Sciences Building, University of Warwick, Coventry CV4 7AL, UK

Tel: 44-24-7615-1027Ｅ-mail: Yuxin.Li@warwick.ac.uk

\begin{abstract}
Since the "Quality education" was proposed in China in 1997, the Chinese education reform has had some success; however, the resistance of it is also quite obvious. The academic pressure of the students in China is not reduced but increased instead. The paper analyses the resistance of China's education reform and the source of Chinese students' academic pressure from three aspects: China's tradition of academic examinations, one child policy and China's leaping economy.
\end{abstract}

Keywords: Quality education, Academic pressure, Resistance of education reform

\section{Introduction}

It has been 13 years since "Quality Education" as opposed to "Examination-oriented Education" in China was proposed in 1997. Many Chinese scholars have realised the harm of the "Examination-oriented Education" and the importance of the "Quality Education". For example, some researchers found that on the one hand, Chinese students won many awards in international Olympic competitions of Math, Physics, Chemistry and other Sciences, however, on the other hand, Chinese students are comparatively lack of innovative ability and there has not been a single Nobel Prize winner in China so far. The current situation of the Chinese education has obtained much attention of China's decision makers. Two representative documents for China's education reform were introduced, respectively, on the $24^{\text {th }}$ December 1998 by Chinese Ministry of Education named "21st Century Action Plan for Invigorating Education" and on the $13^{\text {th }}$ June 1999 by China's Central Committee and State Council named "Decisions on Deepening Education Reform and Promoting Quality Education". The two documents was followed by some methods of innovative education reform and quality education reform which had some success but meanwhile the resistance is also quite obvious. For the reasons of the resistance, China's cultural background and pressure from the Chinese families are inignorable. For example, in order to push the quality education reform, reduce the harm of examination-oriented education, the Chinese government required primary and secondary schools to increase students' leisure time, cancel extra classes outside school and remove score ranking. Also, students should choose their secondary schools based on residential regions instead of being chosen by score ranking. However, the traditional thinking of hierarchy in the Chinese culture has a large impact on education. Every region has their own public recognised key schools and non-key schools, although this distinction may not be accepted by the government. The standard of the distinction between key schools and non-key schools is the transition rate. Thus in order to get good students, schools give extra classes outside school time secretly for a higher transition rate and admit students based on applicants' special skills, levels and numbers of outside school awards (especially their Olympic Maths scores which becomes the key evidence of students' ability) given the fact that the governments have removed the entrance exams. From parents' aspect, in order to get their children admission to key schools, they would spend a fortune to buy houses near the key schools, and the price of the houses near those key schools increase as a result. Under these circumstances, after-school classes focusing on Olympic Maths and other special skills emerged. For the success of their children, parents send their children from the in-school classes directly to various after-school classes, ignoring children's individual ability. For such reasons, the burden on children is not decreases, but increased more and more. It is not surprising to say that nowadays in China, the most tired people are children. Their childhood which is supposed to be pressure-free has been deprived by various after-school classes and classes for special skills. 


\section{Reasons for the Resistance of China's Education Reform}

The education reform in China is difficult for some deep-rooted reasons:

\subsection{China's tradition of academic examinations is an important source of academic pressure.}

In 1978, China resumed the university entrance examination. The "entrance examination" has then become a top priority for many families in China. The only goal for Chinese children who study very hard for more than ten years is to gain a good university entrance examination score. One of the most important social indicators of the success of families is what type of university their children go to. The measure for the quality of a school is also about the percentage of students going to universities (transition rates). Furthermore, the local transition rate has also become an indicator of the political performance of the local government; as a result, some places weigh the transition rate as important as the GDP.

The university entrance exam, like a baton or a magic spell, relates all types of study closely to it. Before the exam, there are extra classes and prolonged school time, teachers make a guess of the contents of the exam paper and give students a lot more homework. In addition, review classes before the exam are based on the past papers and a strategy called "sea of exercises" are commonly adopted to make students do as many exercises as possible which is accompanied with excessive mechanical memory training. The countdown board stating the days left before the university entrance exam will be hang in the classroom and the students could only have a few hours' sleep a day. Many schools, teachers, parents and students admit that the study before the entrance exam to university is a purgatory-style study that is against human nature and is a physical and mental destruction for the human being. Every July, the hot topic of the community is about the university entrance exam and the focus is the students who are to take it. One more point of the score may decide a person's whole life making students and families unbreathable. Therefore, for the existence of the university entrance exam, the July in China are known as "Black July". Before 1998, the transition rate from high school to university was very low, thus the university entrance exam can be described as "thousands of people trying to run simultaneously through a single bridge which can only accommodate one person at a time" and anyone who could make it will have a secured life. After 1998, the universities in China expended the admission numbers, and the fight to universities became the fight to good universities.

Many Chinese people believe that the reason for the resistance of the education reform in China has its stem in China's traditional culture background of exams. The examination system was introduced in the Sui Dynasty in China over 1400 years ago. At that time, an "Imperial Exam System" was established and it was not until Guangxu thirty-one years of the Qing Dynasty (1905) that the "Imperial Exam System", which had last for over 1300 years, was formally abolished. The "Imperial Exam System" selected government officers among civilians from various levels through a special exam called "Ba Gu Wen" exam, the first one as a "champion" would be elected to the Royal Palace. "From a poor guy in the morning to someone going to the royal palace in the evening" was the dream of ancient scholars and the description of "play no attention to outside matters, only focus on saints book" vividly depicted the life of them. A lot of people take the exam from they were very young until very old, because this was the only way to get a better life. The content of the exam is mainly about classic Confucianism. There is an old story about an old man who finally passed the exam when he was 54 years old but went mad immediately when he heard the good news because of being too excited. This story gives a perfect example on how the exam impacted on people at that time. The "Imperial Exam System" which lasted for over 1300 years also had its positive side and had made great contribution to the fairness in competition, political stability, Chinese civilisation and the spread of Confucian culture. However, the content of the examination focused on text learning rather than practicing, mechanical memorising rather than innovation, and had over emphasised on exam scores and competition because of a narrow path to success, it had plant exams and competition deeply into our national culture and thus affect the contemporary education reform.

\subsection{Pressure for Success on Children caused by "One Child Policy"}

Traditional Chinese culture attaches great value to families. Grandparents have the responsibility and obligation to raise their grandchildren, children have the responsibility and obligation to support their parents, otherwise, they will be ostracised by the community and ridiculed by other people. For a long time, "continue the family line" has been the primary task of a family member. The "One Child Policy", began in 1979, led to the emergence of tens of millions of "one child" in the late 70 s and early 80 s of the last century. This is a special population which arised due to the extreme measures taken under the pressure of a high increasing rate of population. The one-child population, as a consequence of the reproductive behaviour of the previous generations, appeared in China with the imprint of the one-child policy. The "One Child Policy" is the last resort for China's population problem and it has made the one-child issues in China different from other western 
countries at the very beginning. For a country like China which has been affected deeply by traditional culture, when the weight of the family and meaning of offspring are integrated into one child, the problems of the education of the one-child are inevitable. The one-child education in China has the same meaning with the one-child education in western world in terms of psychological characteristics and personality development, and it also has its own special meanings related to Chinese social culture and values in terms of "Succeeding problem", "Destructive Enthusiasm" and "excessive indulgence" issues.

The "One Child Policy" has been adopted in China for over 30 years, according to the statistical record, it has lowered the population by 350 million and made a great contribution to the population and social burden control and has improved the quality of births. However, its drawbacks are also apparent, such as population aging problem and a serious imbalanced sex ratio. Another drawback of the "One Child Policy" is its impact on the psychological characteristics and personality development of those one-child children. A test using a Cartel 16PF test methods was conducted on 1060 undergraduates who started their university in 1994 and 1995 in Xi'an Electronic Science and Technology University and Xi'an Jiaotong University. The study found that the one-child students are less sophisticated, less sensitive and less experimental than the non-one-child student. They are more likely to rely on others, more likely to be excited and have more courage to do things than the non-one-child students. Another test which also used the Cartel 16PF test methods was adopted in an investigation on all of the 106 undergraduates from the computer science department who started their university in 1996 in Harbin Engineering University. The results showed that stability, social responsibility, sophistication and independence of the one-child students as compared with non-one-child students are poorer. The anxiety, reliance and boldness of the one-child students tend to show polarization. A sample survey on the education of the one-child families found that those one-child families' has five problems regarding the education of their children: too much expectation, excessive indulgence, excessive interference, low quality of parental education and education from the elderly. In most of the Chinese families, children are raised up by grandparents while parents are working, and the grandparents' love is more of a spoiled love without condition. The "One Child Policy" made the only child become the focus of a family and the one-child children became the "little Emperor, Little Princess" of the family. Because of the traditional concept of "continuing the family line" and "hard to raise a single child" that occupied the mind of parents and grandparents, the one-child children who were supposed to be educated became the dominator of the family and enjoyed all the family rights. From another point of view, the one-child children are the spiritual sustenance and the only hope of many families, although they receive more material comforts, they are not happier than their parents because of the academic pressure from the desire for success.

In October 1998, the China Youth Research Centre did a national wide survey in 12 cities on 3284 primary and secondary students who are the one-child and their parents, using tools like learning needs table, self-acceptance scale, character and interests needs tables. They further did an in-depth analysis of the personality status of the one-child. As indicated by a research group focusing on "China's one-child children's personality development" in their report, a multiple-response survey question showed that 77 percent of the interviewed one-child children claimed that they learn because they need to repay their parents, although whether the need to repay parents is a good characteristic that deserves development is still controversial. 66 percent of the one-child children indicated that they need to study for development. However, cognitive needs, which are supposed to be the most important internal driving force for study, received the lowest percentage, only $33 \%$. Meanwhile, correlation analysis also found that academic pressure caused the one-child's personality flaws: as shown by the children's self-acceptance scale, only 15.6 percent of the students interviewed had strong satisfaction towards their study due to the excessive academic pressure.

\subsection{A Leaping Economy Shifts Families’Emphasis towards Children's Education}

China has been experiencing a great leaping-forward economic development after China's economic reform and opening up of the economy. The children nowadays can no longer imagine the poverty in the previous generation when their parents still had to strive for proper meals and warm clothes, and lost many opportunities such as going to universities. Many parents placed their unrealised dreams as a young man on their children and brought too much pressure on their children. "Hoping their children to be the best" is a general thinking of Chinese parents. Parents take it for granted that children are now living without worries, there is no reason not to study hard and children should bring good scores back to prove their successes and to reward their parents. The ignorance of children's emotion, mechanical learning, and excessive study has brought too much pressure on children.

Since the 1990s, family education expenditure increases at an average rate of 29.3 percent every year which is faster than the increase of family income, higher than the increases of other consumption expenditure and also 
higher than the growth of China's GDP. The proportion of expenditure on education out of total family expenditure, either in absolute levels or rate of increase, is much higher than some developed countries. For example, in 2005, the average annual per capita expenditure of urban families on educational, cultural and recreational services reached 1098 Chinese Yuan (RMB), increased 6.3 percent compared to the previous year, taking up 13.8 percent of urban families' total annual expenditure. Compared to 4.68 percent in 1995 it shows that family investment in education has become prevalent, indicating that family's focus on investment in education has shifted to out-of-class training. According to a sample survey conducted by "Native and Foreign Students" magazine of Guangzhou in 2004, over 50 percent of secondary school students in Guangzhou attended extra-curricular training. This proportion reached to 80 percent for elementary school students. In 2006, a survey conducted in Tangshan City on elementary and secondary students showed that 70 percent of secondary school students attended extra-curricular training, only 10 percent of elementary school students did not participate in extra-curricular training. The extra-curricular training is mainly focused on Olympic Maths, English, Chinese, and some other subjects of interests. As a result, the day time education has been largely extended leaving great pressure on students. As indicated in "China Report 2009" conducted by Peking University: Students in Beijing have the longest study hours per day, 14.4 hours; students in Shanghai have the second longest study hours per day, 13.2 hours; the next one is students in Guangdong, 11.9 hours per day. For the success of children in the future, parents put a lot of money and effort on children's education without any hesitation. Many people believe that quality education means not only do children need to be good with their academic work, but also children should learn how to sing, how to dance, how to play musical instruments and chests, and how to write and draw. As a result, parents send their children to various classes for special skills besides the normal school education, without considering children's own ability and willingness. For a city child, they normally go to some special classes for skills from age 4. A 5-year-old child normally goes to 5 different skill classes in a week: dance class, piano class, story-telling class, presentation class, Calligraphy class and so on. It is said that the most profitable market in China now is the "child education market". To meet the parents' need of having a successful child, various child education classes emerged, however, some of them are with very poor quality, only there for profits. The excessive mechanical training and learning take up most of children's leisure time which was supposed to be thinking and gaming time, and this spoon-feeding education to some extent hindered the development of creativity and spirituality.

A large part of the resistance of the education reform in China is from families. For example, some schools responded to the government's call for an education reform with some quality education reform pilot projects which aim to increase the content of education with innovation, aim to cancel classes that are only for examination, and enable students with more flexible study time. However, voices of opposition came from parents who were worried that those actions would affect children's test scores and entrance exam scores to university. So parents required schools to give extra classes and do not take their children as a trial of the education reform. Otherwise, it would have bad impact on children's university entrance exam and their future. Many education reforms are thus failed because of the opposition from parents.

The Chinese government has noticed the seriousness of the issue. Recently, Chinese Minister of Education, Rengui Xue, proposed that China must transform from a large education country to a powerful education country with a focus on replacing exam-oriented education with quality education, eliminate the negative impacts of exam-oriented education and develop innovative talents. To do this, some actions have been taken, such as allowing some "key" universities choose their own students rather than from a unified national university entrance examination; enriching the content of primary and secondary school education ect. Shandong is the most radical province in this round of the quality education reform. The Local government decided to introduce a complete education reform to the secondary school entrance examination in 2010, replacing the original entrance examination with the educational grading system; university entrance test scores will become personal privacy and is no longer open to the public; and begin to implement "No Score" evaluation to the routine examination. Whether those new policies will have positive effects remains to be seen, however, if the new policies can be implemented successfully, it will be a precedent for China's education and will greatly reduce the pressure of school students and free children from the academic pressure. As described by Zhiyong Zhang, deputy director of Department of Education in Shandong Province, the ultimate goal of the new policy for the quality education reform can be summarised with "Three Returns": return the leisure time and holidays to children, return health to children, return innovative ability to children. No wonder, such changes must go through a complex process and will encounter various difficulties because of the large population in China and complexity of China's current situation. However, the government has determined and as stated by Rengui Xue: China's education reform has become extremely urgent and there is no way back." 


\section{References}

Zhu, X. (2008). An Analysis on Emotional Education. Peoples Education Press.

The Research Group for "The Personality Development of the One-Child in China" (1998). A Report on The Situation of the Personality Development for the One-Child in China. Education Studies, 10.

Feng, X. (2002). The Studies on the One-Chile in China: Review and Prospects. Jianghai Magazine.

Luan, L. (2001). An Analysis on the Urban Family Education. Education and Economy, 2.

Chu H. (2007). A Study on the Content and Structure of Families' Education Expenditure in Early Childhood Education. Educational Science, 2.

Li, X (2008). School Choice Behaviour in Compulsory Education and Equality of Educational Opportunities. Education Studies, 3.

Yu, G. \& Chen, Shi. (2001). The Relationships between Academic Pressure of Elementary School Students, Academic Success and Adaption Behaviour. Psychology Studies, 3.

Tu, Y. (2008). Children's Happiness and Education. Educational Development Studies, 1. 